\title{
N2 fixation, nutrient accumulation and plant growth promotion by Rhizobacteria in association with oil palm seedlings.
}

\begin{abstract}
An experiment was conducted in undrained poly bags under glasshouse conditions to quantify the $\mathrm{N} 2$ fixing capacity ( $15 \mathrm{~N}$ isotope dilution method) of plant growth promoting rhizobacteria (Azospirillum and Bacillus spp.) in association with oil palm seedlings. Effects of inoculation on nutrient uptake and plant growth promotion will also be observed. The experiment was arranged in a randomized complete block design with five replications and harvested at 390 days after planting. The treatments involved were: 1) killed Azospirillum brasilense (Sp 7), 2) killed Sp 7; + inorganic-Ni, 3) Sp 7, 4) A. lipoferum (CCM 3863), 5) locally isolated rhizobacteria UPMB 10, and 6) UPMB 13 inoculation. Results showed that inoculation of the rhizobacteria could contribute up to $20-50 \%$ of the total nitrogen requirement of the host plant through $\mathrm{N} 2$ fixation process. Besides that, the inoculation process had also stimulated accumulation of nutrient and plant growth (tops and roots) comparable to the control with full inorganic nitrogen (Ni) fertilization after 390 days of growth.
\end{abstract}

Keyword: Biofertilizer; Bioenhancer; Elaeis guineensis; 15N dilution; Rhizobacteria. 